\title{
O uso de suplementos alimentares por praticantes de atividade física no município de Juiz de Fora - MG e frequência de cálculo renal
}

\author{
The use of dietary supplements by practitioners of physical activity in the city of Juiz de \\ Fora - MG and frequency of kidney stones
}
El uso de suplementos dietéticos por practicantes de actividad física en la ciudad de Juiz de Fora - MG y frecuencia de cálculos renales

Ayumi Sakiyama Macedo ${ }^{1 *}$, João Vitor Figueiredo Martins ${ }^{1}$, Lara Thomé Barcellos ${ }^{1}$, Leandro Adati Taira $^{1}$, Luís Henrique Mendes Khouri ${ }^{1}$, Mauricio Martins Moraes Junior ${ }^{1}$, Edilene Bolutari Baptista ${ }^{1}$, Nathalia Barbosa do Espirito Santo Mendes ${ }^{1}$, Guillermo Patricio Ortega Jácome ${ }^{1}$, Letícia Thomé Barcellos ${ }^{1}$.

\section{RESUMO}

Objetivo: Avaliar a frequência de atividade física, o uso de suplementos por praticantes de atividade física em academias de Juiz de Fora - MG e a história de cálculo renal. Métodos: Estudo observacional tipo transversal, em 13 academias de Juiz de Fora. Foram entrevistadas 283 pessoas, entre 18 e 40 anos de idade, ambos os sexos, que concordaram em participar da Pesquisa assinando o Termo de Consentimento Livre e Esclarecido (TCLE). Foi aplicado um questionário contendo questões referentes a dados socioculturais, prática de atividade física, suplementação e alimentação. Resultados: Dos 283 entrevistados, 181 eram do sexo masculino e destes, cerca $55,2 \%$ usavam suplementos. O motivo da suplementação em $80,5 \%$ dos entrevistados foi pelo ganho de massa muscular. Os suplementos mais utilizados foram o WheyProtein seguida da Creatina, estes foram relacionados a formação de cálculos renais. Cerca de 12,2\% dos indivíduos que usavam suplementos tinham história de cálculo renal, sendo encontrado na pesquisa um valor significativo ( $p$-valor $=0,034$ ). Quanto a alimentação, observou-se uma maior ingesta proteica por praticantes de musculação que utilizam suplementos alimentares associados à dieta. Conclusão: É imprescindível que haja uma correta indicação do uso de suplementos por um profissional de saúde para aqueles que realmente necessitam de tais.

Palavras-chave: Suplementos alimentares, Atividade física, Proteínas.

\begin{abstract}
Objective: To evaluate the frequency of physical activity, the supplement use by physical activity practitioners in gyms in Juiz de Fora - MG and kidney stones records. Methods: Observational cross-sectional study in 13 gyms in Juiz de Fora. In this research, 283 people were interviewed, between 18 and 40 years old, both genders, all individuals enrolled who agreed to participate after signing the Informed Consent Form (ICF). It was applied a questionnaire containing questions regarding socio-cultural data, physical activity practice, supplementation and diet. Results: Of the 283 respondents, 181 were male and of these, about $55.2 \%$ used supplements. The reason for supplementation in $80.5 \%$ of respondents was the gain in muscle mass. The most commonly used supplements were WheyProtein followed by Creatine, these were related to kidney stone formation. About $12.2 \%$ of the individuals who used supplements had a history of kidney stones, and a significant value was found in the survey $(p$-value $=0.034)$. Regarding feeding, a higher protein intake was observed by muscle training practitioners who use dietary supplements associated with diet. Conclusion: There must be a correct indication of the use of supplements by a health professional for those who really need such supplements.
\end{abstract}

Keywords: Dietary supplements, Physical activity, Proteins.

${ }^{1}$ Universidade Presidente Antônio Carlos (UNIPAC), Juiz de Fora - MG. * E-mail: ayumi-sm@hotmail.com 


\section{RESUMEN}

Objetivo: Evaluar la frecuencia de actividad física, el uso de suplementos por practicantes de actividad física en las academias de Juiz de Fora - MG y registros de cálculos renales. Métodos: Estudio observacional tipo transversal, en 13 academias de Juiz de Fora. Fueron entrevistadas 283 personas, entre 18 e 40 años de edad, de ambos sexos, que concordaron en participar de la pesquisa asignando el Termo de Consentimiento Libre y Esclarecido (TCLE). Fue aplicado un cuestionario conteniendo preguntas referentes a datos socioculturales, práctica de actividad física, suplementación e alimentación. Resultados: De los 283 entrevistados, 181 eran del sexo masculino e de estos, cerca de $55,2 \%$ usaban suplementos. El motivo de la suplementación en $80,5 \%$ dos entrevistados fue por aumento de masa muscular. Los suplementos más utilizados fueron el Whey Protein seguido de Creatina, estos fueron relacionados con la formación de cálculos renales. Cerca de $12,2 \%$ de los individuos que usaban suplementos tenían historia de cálculo renal, siendo encontrado en la pesquisa un valor significativo ( $p$-valor $=0,034)$. Cuanto a la alimentación, fue observado una mayor ingesta proteica por practicantes de musculación que utilizaron suplementos alimentares asociados a la dieta. Conclusión: Es imprescindible que haya una correcta indicación del uso de suplementos por un profesional de la salud para aquellos que realmente necesiten de tales suplementos.

Palabras-Ilave: Suplementos alimentares, Actividad física, Proteínas.

\section{INTRODUÇÃO}

A realização de atividades físicas tem notória importância para a população, visando melhorias na qualidade de vida, resistência física, prevenção e tratamento de doenças crônicas. $O$ ideal para 0 aprimoramento da saúde é a associação entre a prática de exercícios físicos e uma alimentação adequada, embora muitas pessoas não a façam com êxito, seja por falta de interesse ou de conhecimento. Muitas vezes, o parâmetro para a satisfação pessoal se dá simplesmente por fatores físicos e estéticos, sem levar em consideração a fisiologia do organismo e suas necessidades (SOUZA VM e NAVARRO AC, 2011).

Embora o ambiente das academias ainda favoreça a disseminação de padrões estéticos estereotipados, como o corpo magro, com baixa quantidade de gordura ou com elevado volume e tônus muscular, segundo à ciência que está em constante evolução, sabe-se a real importância do exercício físico, o qual é extremamente benéfico para a qualidade de vida (HIRSCHBRUCH MD, et al., 2012; SABA FKF e BARBANTI VJ,1999). Os indivíduos que estejam fora do padrão, considerado ideal pela própria sociedade, sempre foram muito influenciados a mudarem seus estilos de vida, objetivando o que seria o corpo perfeito perante a sociedade (WITT JSGZ e SCHNEIDER AP, 2011).

Uma alimentação adequada também é imprescindível para atingir uma meta de saúde exemplar, tanto fisiologicamente quanto esteticamente. Visto o reflexo de uma boa alimentação na saúde, a busca tem se concentrado muito em mudanças de hábitos alimentares, principalmente por objetivos relacionados à estética (SOUZA VM e NAVARRO AC, 2011).

Associado à prática da atividade física e boa alimentação, o uso dos suplementos nutricionais surge como um aliado para que os objetivos individuais e melhor qualidade de vida sejam alcançados em um prazo de tempo menor. Segundo o Ministério da Saúde, suplementos nutricionais servem para complementar, com calorias e/ou nutrientes, a dieta diária de uma pessoa saudável, nos casos em que sua ingestão pela alimentação seja insuficiente ou quando a dieta requeira suplementação (CAVA TA, et al., 2012).

Quanto aos malefícios de uma suplementação sem orientação, o excesso de proteínas pode ser prejudicial ao fígado e rins, podendo ser capazes de sobrecarregar tais órgãos, devido à metabolização de aminoácidos e a excreção ocorrerem nestes órgãos, respectivamente (ALVES TO, et al., 2012).

$\mathrm{O}$ uso indiscriminado de suplementos alimentares, principalmente sem o acompanhamento médico e nutricional, pode no futuro trazer danos à saúde do indivíduo (MAXIMIANO CMBF e SANTOS LC, 2017). As recomendações da ingestão diária de proteínas para atletas consistem em 1,2-1,7 g/kg de peso corporal ou $12 \%-15 \%$ do consumo energético total (RODRIGUEZ NR, et al., 2009). 
Frente a este cenário, um estudo feito com ratos, publicado pelo Journal Medicinal Food, demonstrou que, o Whey Protein (WP) o qual tem origem animal, numa dieta hiperproteica (ingerido 13,8 gramas por 100 gramas de massa muscular), pode induzir a acidose intracelular, o que estimula a hipocitratúria (redução da excreção de citrato pela urina) e hipercalciúria (aumento do cálcio excretado pela urina), o que contribui para a nefrolitíase, sendo cálculos formados, basicamente, por sais de cálcio.

No entanto, mesmo com alterações predispostas à litogênese não houve alteração nos marcadores da TFG (taxa de filtração glomerular), principalmente creatinina e ureia, que denotassem algum grau de comprometimento da função renal. Apesar da tendência exacerbada à litíase renal, os rins das cobaias continuaram a funcionar normalmente (nenhuma alteração laboratorial compatível com injúria e perda da função renal).

Ainda em litíase renal, constatou-se que o processo de litogênese é contrabalanceado por uma alimentação rica em frutas e vegetais, que age como um fator protetor. Ao induzir a citratúria e aumentar o valor do $\mathrm{pH}$ urinário estes hábitos alimentares são capazes de diminuir o risco de nefrolitíase e de aumentar o peso hepático e renal (APARICCIO, et al., 2014) (BARATA JLRT, 2017).

Como alternativa, o estudo sugere a substituição do WP pela proteína da soja a qual tem origem vegetal, sendo pobre em aminoácidos sulfúricos, obtendo vantagens nutricionais àqueles que possuem propensão à formação de cálculos, interferindo menos na sua excreção renal.

A alimentação rica em frutas e vegetais, também demonstrou papel importante na diminuição do risco de nefrolitíase por aumentar a citratúria e pH urinário. Concluiu-se, portanto, que uma suplementação baseada em proteína de soja seria o ideal para indivíduos com alto risco de nefrolitíase ao comparado com o WP (APARICCIO, et al., 2014).

A prescrição e o aconselhamento de suplementação são complexas e devem ser realizados por um profissional capacitado levando em conta uma série de fatores como: controle do peso corporal, a ingestão adequada de macro, micronutrientes e líquidos, a satisfação de aspectos sensoriais, cognitivos e psicológicos envolvidos com o estresse da modalidade, além da manutenção da saúde, que deve estar acima de qualquer outro objetivo de performance (DAVIS JM, 2000).

É fato que a indústria de suplementos alimentares fatura mais de milhões de dólares no mundo inteiro. A regulamentação da produção e comercialização desses produtos é feito pela Agência Nacional de Vigilância Sanitária (ANVISA), que prevê a liberação para a comercialização destes, contanto que estejam de acordo com a categoria na qual o produto se enquadra, bem como produzi-los conforme estipulado pela legislação sanitária (SILVA LFM e FERREIRA KS, 2014).

Porém, com base em históricos legais, a maioria dos fabricantes de suplementos alimentares para emagrecimento e ganho muscular, ignora ou perverte as normas nacionais para comercialização no país, sendo estes o mesmo grupo de suplementos com maior índice de irregularidade. Portanto, a decisão da ANVISA de flexibilizar a venda de suplementos com pouca ação fiscalizatória, ao remover a obrigatoriedade de registro de alimentos para fins específicos, pode, consequentemente, aumentar os riscos à saúde dos consumidores.

A popularização do uso de suplementos pode resultar um difícil controle fiscal, elevar a competitividade entre os fabricantes, que podem elaborar propagandas mais ousadas, aumentando a quantidade de vendas (SILVA LFM e FERREIRA KS, 2014).

Sendo assim, considerando que o uso de suplementos, por motivos variados, inclusive estéticos, encontrase em franca ascensão, o acesso facilitado e conhecimento inadequado da população pode tornar a suplementação um risco à saúde, principalmente quando não são respeitadas as contraindicações e não há um acompanhamento profissional adequado, seja ele por meio de nutrólogos, nutricionistas ou até mesmo médicos.

Dessa forma, o presente trabalho tem como objetivo verificar a frequência de atividade física, o uso de suplementos em praticantes de atividade física nas academias do município de Juiz de Fora - MG e fomentar a hipótese de relação entre o uso de suplementos alimentares e litíase renal. 


\section{MÉTODOS}

Foi realizado um estudo observacional tipo transversal sendo a população de estudo composta por 283 entrevistados, todos frequentadores das academias de Juiz de Fora - MG. Foram encontradas 85 academias através de lista telefônica da cidade, sendo selecionadas por sorteio 24 delas, das quais apenas 13 aceitaram participar da pesquisa. Os praticantes de atividade física foram entrevistados na entrada das academias em dias e horários distintos com um questionário elaborado exclusivamente para esta pesquisa, o qual foi dividido em 3 partes: sociocultural, geral e alimentar. O tópico sociocultural é composto por 11 perguntas (nome, idade, data de nascimento, sexo, naturalidade, escolaridade, profissão, peso, altura, IMC (Índice de Massa Corporal).

O tópico geral abordou 15 perguntas que analisaram se o indivíduo fez uso de suplemento, se sim, qual o tipo de suplemento utilizado (BCAA - Branched-chain amino acids, Creatina, Whey Protein, Carnitina, Glutamina, Albumina, Colágeno, HMB - beta-hidroxi-metilbutirato, Maltodextrina, Vitaminas, DHEA desidroepiandrosterona), a quantidade ingerida, a frequência do uso (semanal e diário), o motivo de uso e se há acompanhamento por profissional de saúde, também foram avaliadas a presença de comorbidades que se relacionam com atividade física e suplementação alimentar. Por fim, o tópico alimentar, o qual abordou 1 pergunta com 11 itens sobre o consumo de alimentos por dia da semana e sua quantidade.

O questionário foi recolhido respeitando o sigilo pessoal dos entrevistados e as normas éticas para pesquisa com seres humanos, que no Brasil é regulamentada pela Resolução CNS 466/2012, além de todos os demais critérios de inclusão (pessoas acima de 18 anos e abaixo de 40 anos, que praticam musculação, que frequentam as academias escolhidas, que estejam de acordo com a pesquisa proposta e que aceitem assinar o TCLE (Termo de Consentimento Livre e Esclarecido) e exclusão (pessoas menores de 18 anos e acima de 40 anos, e que não praticam musculação, as que não frequentam as academias escolhidas, que estejam realizando apenas atividade física fora da academia e se recusem a assinar o TCLE). Tal pesquisa apresentou risco médio, por constar perguntas de cunho pessoal propostos e foi submetida à Plataforma Brasil sendo aprovado pelo Comitê de Ética e Pesquisa cujo protocolo é o 3.273.339.

Os dados foram armazenados no programa Access 2013, Microsoft Corporation®USA. Para a análise estatística foi utilizado o programa SPSS 21.0, IBM®SPSS Statistic. Medidas de posição e tendência central foram utilizadas para a descrição de variáveis contínuas e proporções para as variáveis categóricas estudadas. $\mathrm{Na}$ análise com variáveis categóricas para verificar diferenças entre duas amostras independentes foi utilizado o teste de qui-quadrado de Pearson. Nas variáveis contínuas após verificar normalidade através do teste de Shapiro Wilk, em aquelas com distribuição normal foram investigadas diferenças através do teste $\mathrm{T}$ de igualdade de duas amostras independentes. $\mathrm{Na}$ análise do $p$-valor e os intervalos de confiança o valor crítico foi definido em $95 \%$. Os dados foram agrupados e apresentados em tabelas e gráficos.

\section{RESULTADOS}

Foram entrevistadas 283 pessoas, sendo a maioria do sexo masculino, compondo-se de indivíduos entre a faixa etária dos 18 aos 40 anos de idade. Quanto à escolaridade cerca de $82,6 \%$ possuía ensino superior completo, e $31,8 \%$ eram estudantes (Tabela 1).

Tabela 1 - Perfil sociodemográfico dos praticantes de atividade física das Academias da cidade de Juiz de Fora - MG.

\begin{tabular}{cccc}
\hline Características sociodemográficas & Masculino & Sexo & Total \\
& 181 & 102 & 283 \\
\hline Idade (média) & 28,7 anos & 27,6 anos & 28,3 anos \\
Ensino superior (mínimo) & $83,4 \%$ & $81,3 \%$ & $82,6 \%$ \\
Estudante & $28,7 \%$ & $37,3 \%$ & $31,8 \%$ \\
Profissional & $18,8 \%$ & $27,5 \%$ & $21,9 \%$ \\
Empregado & $23,2 \%$ & $21,6 \%$ & $22,6 \%$ \\
Autônomo & $27,6 \%$ & $11,8 \%$ & $21,9 \%$ \\
\hline
\end{tabular}

Fonte: Macedo AS, et al., 2019. 
Em relação ao IMC, 45,9\% dos entrevistados apresentam o mesmo dentro dos padrões de normalidade e o sobrepeso foi maior em homens (49,7\%) que em mulheres (22,5\%). Quanto à prática de atividades físicas, $32,1 \%$ praticam atividade ininterruptamente de 1 a 6 meses, e $52,7 \%$ com a frequência de 3 a 5 vezes por semana, com um tempo gasto nas academias entre 1 a 3 horas por dia.

Mais da metade dos entrevistados afirmaram que os motivos principais que os leva a frequentar a academia é pelo condicionamento físico, ganho de massa muscular e a maioria pela qualidade de vida (Masculino 61,3\%; Feminino 68,6\%) (Gráfico 1).

Gráfico 1 - Principais motivos que levam os participantes do estudo a frequentarem as academias do município de Juiz de Fora - MG.

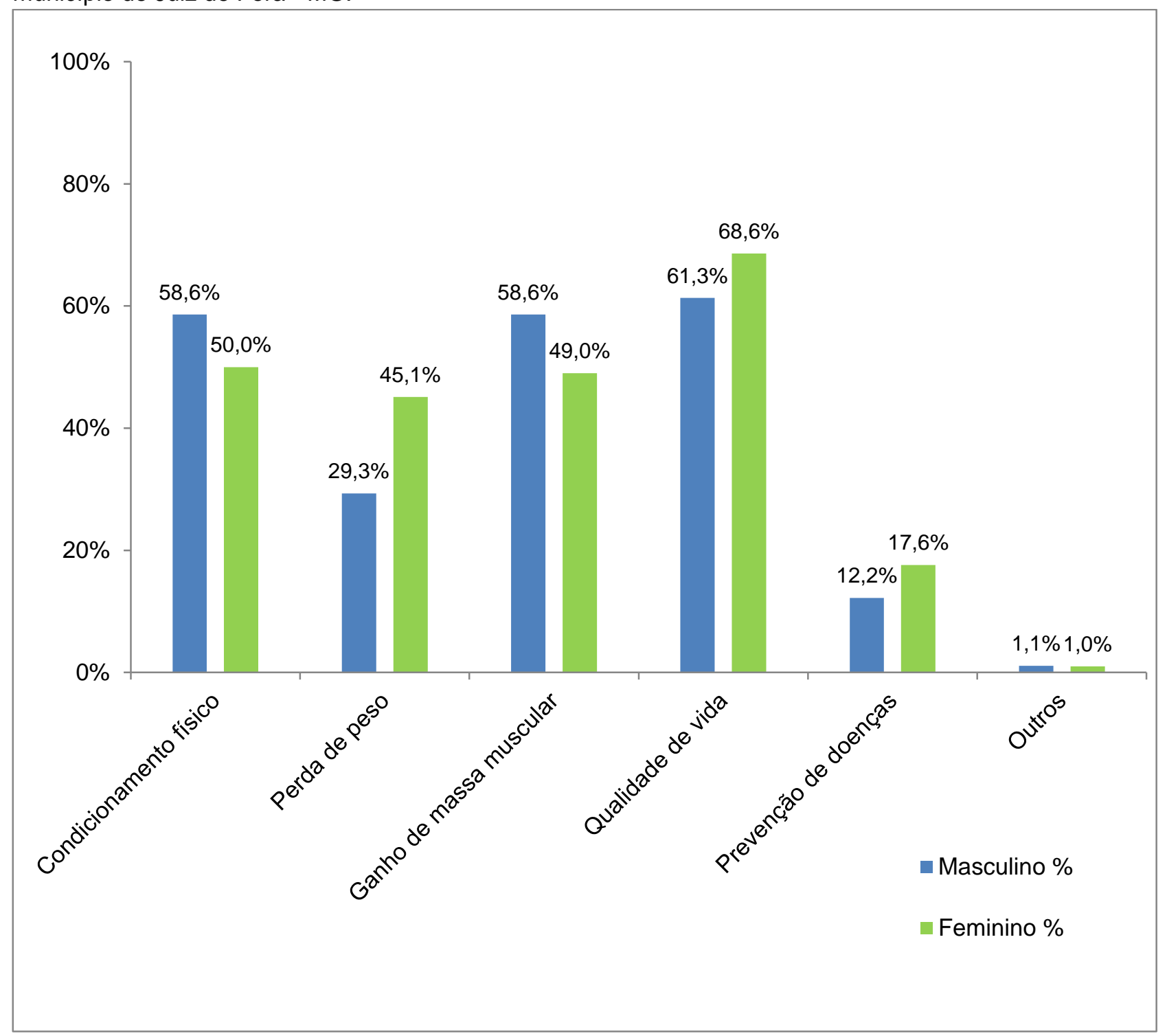

Fonte: Macedo AS, et al., 2019.

Do total de participantes, $47 \%$ dos entrevistados usavam suplementos, a maior parte que os utiliza é do sexo masculino $(55,2 \%)$ sendo o suplemento mais utilizado o Whey Protein $(82,7 \%)$, seguido da Creatina $(50,4 \%)$. Dos entrevistados que usavam suplementos, cerca de $51,1 \%$, tiveram a indicação por nutricionistas e $42,9 \%$ afirmaram ter acompanhamento profissional qualificado. O principal motivo de suplementação foi pelo ganho de massa muscular $(80,5 \%), 63,9 \%$ afirmaram ler o rótulo das substâncias antes do consumo e $61,7 \%$ usam apenas uma vez ao dia. (Tabela 2 e Tabela 3 ). 
Tabela 2 - Uso dos Suplementos Alimentares.

\begin{tabular}{|c|c|c|c|c|c|}
\hline & \multirow{2}{*}{$\begin{array}{l}\text { Masculino } \\
\text { n\% }\end{array}$} & Feminino & \multicolumn{2}{|c|}{ Total } & \multirow[t]{2}{*}{$p$-valor } \\
\hline & & $\mathbf{n}$ & $\mathbf{n}$ & $\%$ & \\
\hline \multicolumn{6}{|c|}{$\begin{array}{l}\text { Uso de suplemento } \\
\text { alimentar }\end{array}$} \\
\hline Sim & $\begin{array}{c}100 \\
55,2 \%\end{array}$ & $\begin{array}{c}33 \\
32,4 \%\end{array}$ & 133 & $47,0 \%$ & 0,000 \\
\hline \multicolumn{6}{|c|}{$\begin{array}{l}\text { Fonte de informação do } \\
\text { suplemento }\end{array}$} \\
\hline amigo & $\begin{array}{c}19 \\
19,0 \%\end{array}$ & $\begin{array}{c}3 \\
9,1 \%\end{array}$ & 22 & $16,5 \%$ & 0,145 \\
\hline nutricionista & $\begin{array}{c}48 \\
48,0 \%\end{array}$ & $\begin{array}{c}20 \\
60,6 \%\end{array}$ & 68 & $51,1 \%$ & 0,125 \\
\hline nutrólogo & $\begin{array}{c}12 \\
12,0 \%\end{array}$ & $\begin{array}{c}2 \\
6,1 \%\end{array}$ & 14 & $10,5 \%$ & 0,264 \\
\hline educador físico & $\begin{array}{c}19 \\
19,0 \%\end{array}$ & $\begin{array}{c}4 \\
12,1 \%\end{array}$ & 23 & $17,3 \%$ & 0,260 \\
\hline internet & $\begin{array}{c}17 \\
17,0 \%\end{array}$ & $\begin{array}{l}2 \\
6,1 \%\end{array}$ & 19 & $14,3 \%$ & 0,103 \\
\hline outros & $\begin{array}{c}7 \\
7.0 \%\end{array}$ & $\begin{array}{c}4 \\
12.1 \%\end{array}$ & 11 & $8,3 \%$ & 0,288 \\
\hline
\end{tabular}

\begin{tabular}{|c|c|c|c|c|}
\hline $\begin{array}{l}\text { Motivo do uso do } \\
\text { suplemento }\end{array}$ & & & & \\
\hline ganho de peso & $\begin{array}{c}11 \\
11,0 \%\end{array}$ & $\begin{array}{l}- \\
-\end{array}$ & $\begin{array}{c}11 \\
8,3 \%\end{array}$ & 0,052 \\
\hline ganho de massa muscular & & $\begin{array}{c}29 \\
87,9 \%\end{array}$ & $\begin{array}{c}107 \\
80,5 \%\end{array}$ & 0,161 \\
\hline melhor desempenho físico & $\begin{array}{c}65 \\
65,0 \%\end{array}$ & $\begin{array}{c}13 \\
39,4 \%\end{array}$ & $\begin{array}{c}78 \\
58,6 \%\end{array}$ & 0,009 \\
\hline $\begin{array}{l}\text { prevenir doenças e } \\
\text { qualidade de vida }\end{array}$ & & $\begin{array}{c}4 \\
12,1 \%\end{array}$ & $\begin{array}{c}15 \\
11,3 \%\end{array}$ & 0,443 \\
\hline deficiências nutricionais & $\begin{array}{c}7 \\
7,0 \%\end{array}$ & $\begin{array}{c}9 \\
27,3 \%\end{array}$ & $\begin{array}{c}16 \\
12,0 \%\end{array}$ & 0,003 \\
\hline acelerar metabolismo & $\begin{array}{c}15 \\
15,0 \% \\
\end{array}$ & $\begin{array}{c}6 \\
18,2 \% \\
\end{array}$ & $\begin{array}{c}21 \\
15,8 \%\end{array}$ & 0,436 \\
\hline \multicolumn{5}{|l|}{$\begin{array}{l}\text { Revisa orientações do } \\
\text { rótulo do suplemento }\end{array}$} \\
\hline Sim & $\begin{array}{c}62 \\
62,0 \% \\
\end{array}$ & $\begin{array}{c}23 \\
69,7 \%\end{array}$ & $\begin{array}{c}85 \\
63,9 \%\end{array}$ & 0,280 \\
\hline \multicolumn{5}{|l|}{$\begin{array}{l}\text { Frequência do uso de } \\
\text { suplemento }\end{array}$} \\
\hline 1 vez ao dia & $\begin{array}{c}60 \\
60,0 \%\end{array}$ & $\begin{array}{c}22 \\
66,7 \%\end{array}$ & $\begin{array}{c}82 \\
61,7 \%\end{array}$ & \\
\hline 2 vezes ao dia & $\begin{array}{c}23 \\
23,0 \%\end{array}$ & $\begin{array}{c}9 \\
27,3 \%\end{array}$ & $\begin{array}{c}32 \\
24,1 \%\end{array}$ & \\
\hline 3 vezes ao dia & $\begin{array}{c}14 \\
14,0 \%\end{array}$ & $\begin{array}{c}1 \\
3,0 \%\end{array}$ & $\begin{array}{c}15 \\
11,3 \%\end{array}$ & \\
\hline outros & $\begin{array}{c}3 \\
3,0 \% \\
\end{array}$ & $\begin{array}{c}1 \\
3,0 \% \\
\end{array}$ & $\begin{array}{c}4 \\
3,1 \% \\
\end{array}$ & 0,134 \\
\hline \multicolumn{5}{|l|}{$\begin{array}{l}\text { Acompanhamento por } \\
\text { profissional }\end{array}$} \\
\hline Sim & $\begin{array}{c}40 \\
40,0 \% \\
\end{array}$ & $\begin{array}{c}17 \\
51,5 \%\end{array}$ & $\begin{array}{c}57 \\
42,9 \% \\
\end{array}$ & 0,169 \\
\hline
\end{tabular}

Fonte: Macedo AS, et al., 2019. 
Tabela 3 - Tipos de suplementação utilizados pelos participantes da pesquisa.

\begin{tabular}{cccc}
\hline Suplemento Alimentar & \multicolumn{2}{c}{ Sexo do entrevistado } \\
& Masculino $(\mathbf{n})$ & Feminino $(\mathbf{n})$ & $\boldsymbol{p}$-valor \\
\hline Whey Protein & 80 & 30 & 0,118 \\
BCAA & 32 & 8 & 0,270 \\
Glutamina & 20 & 4 & 0,228 \\
Creatina & 59 & 8 & 0,000 \\
Albumina & 16 & 2 & 0,121 \\
Colágeno & 2 & 0 & 0,564 \\
Carnitina & 4 & 5 & 0,042 \\
Vitaminas & 5 & 2 & 0,055 \\
DHEA & 36 & 11 & 0,477 \\
Maltodextrina & 2 & 0 & 0,561 \\
Outros & 4 & 1 & 0,637 \\
\hline
\end{tabular}

Fonte: Macedo AS, et al., 2019.

No presente estudo, percebeu-se que a utilização de suplementos alimentares é maior por indivíduos abaixo de 30 anos de idade $(62,4 \%)$, o que se contrapõe aos que suplementam acima desta faixa etária $(37,6 \%)$. Quanto à relação do uso de suplementos com história de cálculo renal, esta esteve mais presente em indivíduos que usavam suplementos (Gráfico 2).

Gráfico 2 - Comparação de história de cálculo renal entre os indivíduos que utilizam e os que não utilizam a suplementação alimentar. (p-valor 0,034) (Correlação de Pearson: $\rho=0,041$ ).

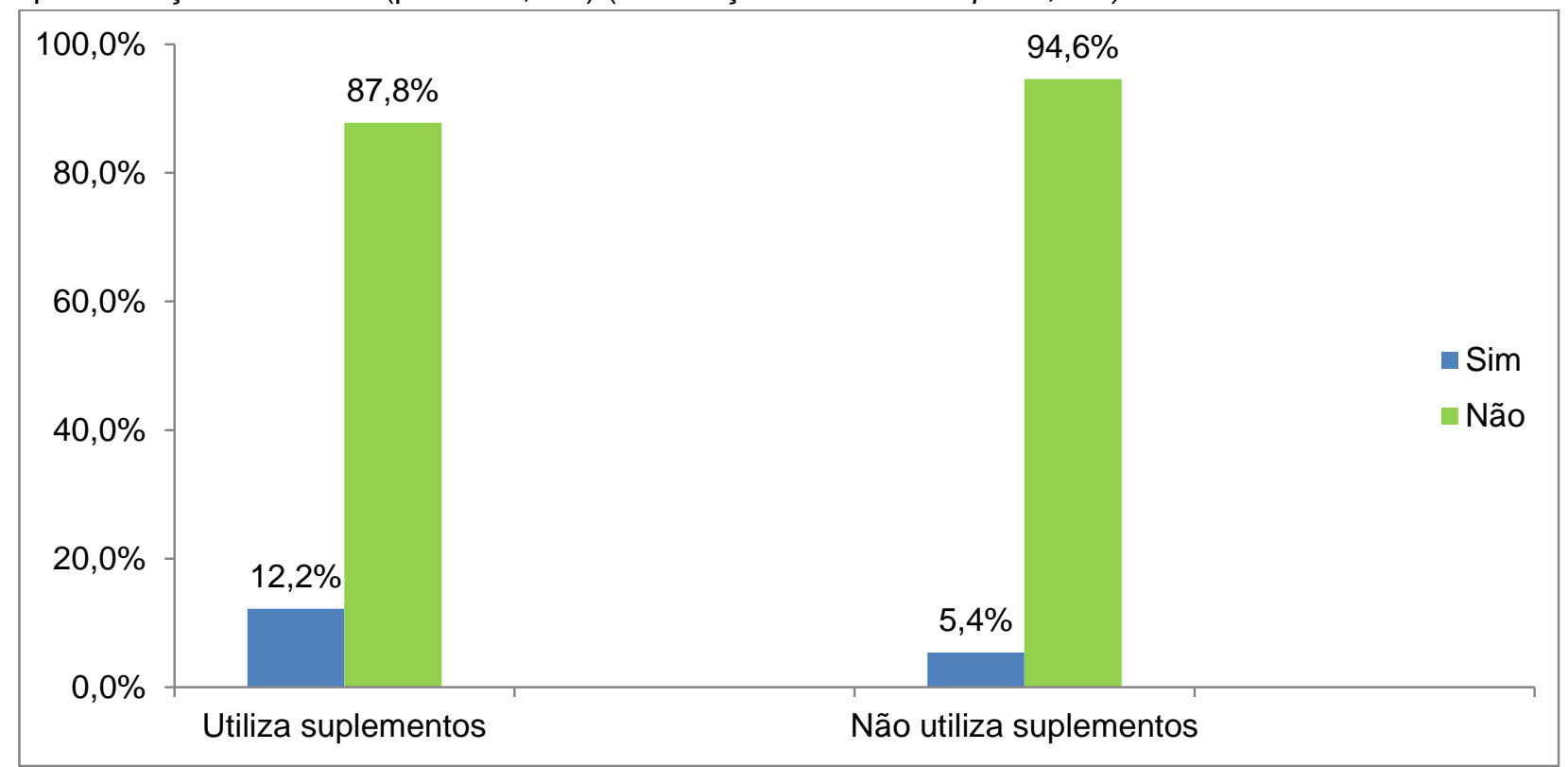

Fonte: Macedo AS, et al., 2019.

A ingesta alimentar de porções maiores é mais comum por indivíduos adeptos à suplementação. Nesse grupo, é notado também a preferência por carne branca, verduras, legumes, raízes e tubérculos e o menor consumo de refrigerantes (Tabela 4). 
Tabela 4 - Comparação entre os indivíduos que fazem uso de suplementos alimentares e os que não fazem uso da suplementação, com o consumo de diferentes tipos de alimentos.

\begin{tabular}{cccccc}
\hline $\begin{array}{c}\text { Tipos de } \\
\text { alimentos }\end{array}$ & \multicolumn{5}{c}{ Uso de suplementares } \\
\hline & $\begin{array}{c}\text { Média } \\
\text { (dias) }\end{array}$ & $\begin{array}{c}\text { Sim } \\
\text { Porção } \\
\text { grande }\end{array}$ & $\begin{array}{c}\text { Média } \\
\text { (dias) }\end{array}$ & $\begin{array}{c}\text { Não } \\
\text { Porção } \\
\text { grande }\end{array}$ & p-valor \\
\hline $\begin{array}{c}\text { Carnes } \\
\text { brancas }\end{array}$ & 4,7 & $22,6 \%$ & 3,6 & $10,0 \%$ & 0,000 \\
Carnes & & & & & \\
vermelhas & 3,5 & $20,3 \%$ & 3,3 & $9,3 \%$ & 0,283 \\
Embutidos & 1,0 & $1,5 \%$ & 1,2 & $0,0 \%$ & 0,257 \\
Laticínios & 4,8 & $12,8 \%$ & 4,6 & $8,0 \%$ & 0,348 \\
Verduras & 5,4 & $23,3 \%$ & 5,1 & $16,7 \%$ & 0,330 \\
Legumes & 4,8 & $12,8 \%$ & 4,6 & $14,0 \%$ & 0,445 \\
Raízes e & 5,0 & $15,8 \%$ & 4,1 & $8,7 \%$ & 0,000 \\
Tubérculos & 4,5 & $8,3 \%$ & 4,4 & $6,7 \%$ & 0,713 \\
Leguminosas & 4,8 & $14,3 \%$ & 5,2 & $11,3 \%$ & 0,126 \\
Cereais & 4,8 & $14,0 \%$ & 4,9 & $12,8 \%$ & 0,754 \\
Frutas & 1,2 & $3,8 \%$ & 1,1 & $4,0 \%$ & 0,785 \\
Refrigerantes & & & & &
\end{tabular}

Fonte: Macedo AS, et al., 2019.

\section{DISCUSSÃO}

Conhecer o perfil dos praticantes de atividade física e usuários de suplementos alimentares, pode contribuir para direcionar a conscientização ao público alvo e alertar quanto a possíveis danos à saúde, principalmente casos de litíase renal.

Sabendo que a dieta ocidental, usualmente, possui alta ingesta proteica e sua necessidade de suplementação não é comum, o seu excesso pode causar o aumento da produção de ureia, cólica abdominal, alterações gastrointestinais (diarreia) e aumentar o risco de desidratação (CORREARD MFP, et al., 2017).

Com base nos resultados obtidos, verificou-se que, em relação ao perfil dos participantes da pesquisa há prevalência do sexo masculino com idade média de 28 anos (Tabela 1). A prevalência do sexo masculino e a média de idade encontrada no presente estudo corrobora com os dados obtidos nos estudos passados de Alves TO et al., 2012 e de Correard, MFP et al., 2017.

O IMC, índice usado para discriminar os entrevistados, frequentemente é criticado por não compreender a realidade principalmente quando utilizado em atletas. Em contrapartida, em estudo realizado pela universidade de Bristol e publicado na JACC (Journal of The American Collegy of Cardiology) no qual participaram 2840 jovens cujos IMC e DEXA (densidometria de composição corporal) foram analisados aos 10 e 18 anos de idade destaca que tanto o IMC quanto a DEXA forneceram dados semelhantes e ambos são efetivos para rastreio geral da população tanto para obesidade quanto para dislipidemia porém, pela própria facilidade e custo-benefício do método, o IMC se destaca (BELL JA, et al., 2018). O IMC é ideal para amostras numerosas, porém insuficiente para atendimento individual (REZENDE FAC, et al.,2010).

Sabe-se que o uso de suplementos por motivos distintos, encontra-se em crescimento, devido ao fato de que há uma significativa importância dada à aparência, corpo e estética. Desta forma, o culto ao que, muitos julgam ser belo é predominante, o que reflete em um número cada vez maior de pessoas utilizando estes produtos associados à musculação. O estudo de Maximiano CMBF e Santos LC (2017) comprova que cerca de $51,2 \%$ dos entrevistados utilizam suplementos sendo este, similar aos dados encontrados no presente estudo (47\%) (Tabela 2).

Verificou-se que, entre os homens, houve maior predisposição em buscar à academia não apenas para hipertrofia muscular, mas para condicionamento físico e qualidade de vida (Cava TA, et al., 2012; Maximiano CMBF, Santos LC, 2017). Além disso, segundo Cava TA, et al., (2012), homens também tendem a utilizar 
mais suplementos pela ambição de melhorar sua força, desempenho físico e tônus muscular. Sendo assim, estes foram predominantes no uso de suplementos alimentares, como comprovado pela pesquisa de Hirschbruch MD, et al., (2008) reforçado pelos resultados de Pontes MCF, (2013) e pelo atual estudo. Ainda na pesquisa de Maximiano CMBF e Santos LC (2017), foi demonstrado que o suplemento mais utilizado e preferido pelos praticantes de musculação é o Whey Protein (WP), corroborando assim com os resultados do presente estudo. Sua fórmula reúne proteína do soro do leite de vaca, aminoácidos essenciais e não essenciais, como a leucina, que oferece com um de seus benefícios a redução da perda de massa muscular.

De acordo com as fontes de informações dos participantes, nota-se considerável predomínio em usuários de suplementos alimentares com indicação por parte de nutricionista, sendo a adesão pelo sexo feminino $(60,6 \%)$ e pelo sexo masculino $(48,0 \%)$ com base nos dados da pesquisa demonstrados no Gráfico 2 . Vale ressaltar, que houve um número considerável de participantes com ensino superior (82,6\%) (Tabela 1). Supõe-se que, estes indivíduos, possam ter uma melhor instrução quanto ao uso dos suplementos associados à uma dieta preestabelecida por nutricionistas, profissionais e afins mantendo um acompanhamento constante.

Ressalta-se também, que o consumo dessa substância em doses que ultrapassem $5 \mathrm{~g} /$ dia não é recomendado, mesmo que para homens saudáveis, pois não há evidências científicas suficientes que garantam a segurança da ingestão acima dessa dosagem, em longo prazo (Poortmans JR e Francaux M, 2000). Já para Hattori, et al., (2017), o consumo de suplementos de WP ou albumina por indivíduos saudáveis em doses habituais (uma colher/dia) durante 3 dias, sob condições de um nível normal de ingestão de proteínas, não induziu alterações nos valores medianos dos parâmetros urinários litogênicos. Mas mesmo assim, diferentes estudos apontam que ainda há evidências científicas insuficientes para se afirmar que a suplementação alimentar possa apresentar riscos e causar danos em indivíduos saudáveis (Gualano B, et al., 2007; Mazon JM, et al., 2018; Poortmans JR e Francaux M, 2000; Silva LFM e Ferreira KS, 2014).

Na pesquisa atual, o índice de nefrolitíase foi maior em indivíduos que usavam a Creatina e o WP, corroborando com a hipótese de diversos estudos, os quais abordam que um consumo exacerbado de suplementos à base de creatina possa causar danos a um rim previamente doente (APARICCIO VA, et al., 2014; GUALANO B, etal., 2007; BASIRIC N, et al., 2002; EDMUNDS JW, et al., 2001). Já no estudo de Lugaresi e colaboradores (2013), foi concluído que após a realização de uma análise da suplementação de creatina por 3 meses, não houve efeito prejudicial sobre a função renal, ainda que associado à um consumo exacerbado de proteínas. Assim é necessário a análise a longo prazo desses indivíduos, para que haja uma conclusão mais concreta a respeito das repercussões que a suplementação pode ou não ocasionar ao Sistema Renal.

A literatura sugere que somente cerca de $5 \%$ dos usuários de suplementos têm histórico de cálculo renal (Correard MFP, et al., 2017). Dentre os entrevistados, dos indivíduos praticantes de musculação que fazem uso de suplementos observou-se que 12,2\% possuíam história de cálculo renal e, em contrapartida, dos indivíduos praticantes de musculação sem o uso de suplementação, somente $5,4 \%$. Sendo a diferença encontrada estatisticamente significativa (Gráfico 2).

É de conhecimento geral que devido a modismos, muitas pessoas se colocam em dietas pré-estabelecidas e não individualizadas, sem acompanhamento profissional, na expectativa de perder medidas ou de aumentar a massa muscular. Isso pode ser observado perante a adoção de dietas com os hiperproteicos e a remoção dos carboidratos constatado por Moreira FP e Rodrigues KL (2014) e também pela atual pesquisa.

\section{CONCLUSÃO}

Dessa forma, o presente trabalho permitiu verificar a frequência de atividade física e uso de suplementos em praticantes de atividade física nas academias do município de Juiz de Fora - MG. Conclui-se que menos da metade dos entrevistados, usavam suplementos, sendo a maior parte do sexo masculino e por indicação de nutricionistas. Entre os praticantes de musculação, a associação dieta e exercício físico para alcançar suas metas é comum, porém nota-se que dentre os praticantes, aqueles que usam suplementos optam frequentemente por porções maiores principalmente, de carne branca e verduras. Em relação aos indivíduos que não utilizam suplementos, aqueles que fazem o seu uso, tinham mais frequentemente, história de cálculo 
renal. Diante disso, cabe investigar se o uso e prescrição dos suplementos alimentares é feito de maneira correta, uma vez que muitos usuários tendem a possuir pouco conhecimento nutricional.

\section{REFERÊNCIAS}

1. ALVES TO, et al. Estimativa do consumo de proteínas e suplementos por praticantes de musculação em uma academia da baixada fluminense, Rio de Janeiro. Corpus et Scientia, 2012; 8(1): 1-10.

2. APARICCIO, et al. Whey Versus Soy Protein Diets and Renal Status in Rats. Journal of medicinal food, 2014; 17(9): 1011-1016.

3. BARATA JLRT. Dietas Hiperproteicas Metabolismo, Efeitos, Segurança e Suplementação. Dissertação (Mestrado em Medicina) - Universidade da Beira Interior, Covilhã, 2017; 47p.

4. BASIRIC N, et al. Effects of oral creatine supplementation in patient with MELAS phenotype and associated nephroathy. Neuropediatrics, 2002; 33(3): 157-161.

5. BRAGGION GF. Suplementação alimentar na atividade física e no esporte: aspectos legais na conduta do nutricionista. Nutrição Profissional, 2008; 4(17): 40-50.

6. CAVA TA, et al. Consumo excessivo de suplementos nutricionais entre profissionais atuantes em academias de ginástica de Pelotas, Rio Grande do Sul, 2012. Epidemiol. Serv. Saúde, 2017; 26(01): 99-108.

7. CORREARD MFP, et al. Uso de suplementos por praticantes de atividade física de uma academia na cidade Pindamonhangaba - SP. Rev UNILUS Ensino e Pesquisa, 2017; 14(36): 265-267.

8. DAVIS JM. Nutrition, neurotransmitters and central nervous system fatigue. In: Maughan, R.J. (ed.) Nutrition in Sport. Oxford: Blackwell science Ltd. pp. 171-183, 2000.

9. EDMUNDS JW, et al. Creatine supplementation increases renal disease progression in Han: SPRD-cy rats. Am J Kidney Dis, 2001; 37(01): 73-78.

10. FONSECA AC, et al. O perigo dos suplementos alimentares. Revista Viver. Hospital SírioLibanês.Abril/junho,2014,5:14-18. Disponível em: https://www.hospitalsiriolibanes.org.br/institucional/publicacoes/Publicacoes/revista- viver-edicao-5.pdf. Acesso em: 8 out. 2018.

11. GUALANO B, etal. A suplementação de creatinina prejudica a função renal? Rev Bras Med Esporte, 2007;14(1): 68-73

12. HATTORI, et al. Whey protein and albumin effects upon urinary risk factors for stone formation. Springer international publisher science, technology and medicine, 2017; 45(5): 421-428.

13. HIRSCHBRUCH MD, et al. Consumo de Suplementos por Jovens Frequentadores de Academias de Ginástica em São Paulo. Rev Bras Med Esporte, 2008;14(6): 539-543.

14. LACERDA FMM, et al. Fatores associados ao consumo desuplementos nutricionais por frequentadores de academias. Rev Saúde Pública, 2015; 49(63).

15. LUGARESI, R, et al. Does long-term creatine supplementation impair kidney function in resistance-trained individuals consuming a high-protein diet? Journal of the International Society of Sports Nutrition, 2013; 10(1): 26.

16. MAXIMIANO CMBF, SANTOS LC. Consumo de suplementos por praticantes de atividade física em academias de ginastica de Sete Lagoas - MG. Revista Brasileira de Nutrição Esportiva, 2017; 11(61): 93-101.

17. MAZON JM, et al. Avaliação da ingestão de proteína e conhecimento sobre nutrição de praticantes de musculação em Erechim-RS. Rev Bras de Nutrição Esportiva, 2018; 12(72): 463-471.

18. MOREIRA FP, RODRIGUES KL. Conhecimento nutricional e suplementação alimentar por praticantes de exercícios físicos. Rev Bras Med Esporte, 2014; 20(5): 370-373.

19. PONTES MCF. Uso de suplementos alimentares por praticantes de musculação em academia de João Pessoa - PB. Rev Bras Nutrição Esportiva, 2013; 7(37): 19-27.

20. POORTMANS JR, FRANCAUX M. Adverse effects of creatine supplementation: fact or fiction? Sports Med, 2000; 30(3): 155-170.

21. RODRIGUEZ NR, et al. Position of American Dietitic Association, Dietitians of Canada, and American College of Sports Medicine: nutrition and athletic performance. J Am Diet Assoc.; 2009;109(3): 509-527.

22. SABA FKF, BARBANTI VJ. Determinantes da prática de exercício físico em academias de ginástica. Dissertação (Mestrado) - Escola de Educação Física e Esporte. Universidade de São Paulo, São Paulo, 1999; 56 p.

23. SHAO A, HATHCOCK JN. Risk assessment for creatine monohydrate. Regul Toxicol Phamacol, 2006; 45(3): $242-$ 251.

24. SILVA LFM, FERREIRA KS. Segurança alimentar de suplementos comercializados no Brasil. Rev Bras Med Esporte, 2014; 20(5): 374-378.

25. SOUSA MAQ, AZEVEDO CHG. Suplementação de creatinina e possíveis efeitos colaterais. Rev Bras de Nutrição Esportiva, 2008; 2(9): 99-105.

26. SOUZA VM, NAVARRO AC. A educação alimentar dos frequentadores de academias de ginástica em Salvador - BA: alimentação associada ao exercício físico. Revista Brasileira de Nutrição Esportiva, São Paulo. 2011; 5(25): 51-61.

27. WITT JSGZ, SCHNEIDER AP. Nutrição estética: valorização do corpo e da beleza através do cuidado nutricional. Ciênc saúde coletiva, 2011; 16(9):3909-3916.

28. BELL JA, et al. Associations of Body Mass and Fat Indexes With Cardiometabolic Traits. Journal of the American College of Cardiology, 2018; 72(24): 3142-3154.

29. REZENDE FAC, et al. Aplicabilidade do índice de Massa Corporal na Avaliação da Gordura Corporal. Rev Bras Med Esporte, 2010; 16(2): 90-94. 